\title{
CÓMO LA COMPRENSIÓN CULTURAL E INDIVIDUAL DE LOS PROCESOS DE DESARROLLO Y LOS NIVELES DE CONCIENCIA PUEDEN AYUDARNOS A DAR FORMA A LOS DESAFÍOS DEL TURISMO POSPANDÉMICO
}

\begin{abstract}
Mia Brummer ${ }^{1}$
\section{Resumo:}

A necessidade dos viajantes mudará significativamente, do mesmo modo como as ofertas dos provedores de destinos de viagem depois da pandemia. Mas que ferramentas de avaliação deveremos usar se ainda não podemos predizer até onde irá o mercado? Pode um olhar à compreensão cultural e individual dos processos cíclicos de desenvolvimento e aos níveis de consciência ajudar-nos a dominar os desafios do turismo pós-pandêmico e a encontrar soluções? Neste artigo comparo a história do desenvolvimento do indivíduo, da cultura e do turismo para fazer uma previsão sobre onde pode se desenvolver o turismo pós-pandêmico. Se compreendermos como se desenrolam os indivíduos e as coletividades, que necessidades, meios, desafios e objetivos têm, também poderemos prever o desenvolvimento do turismo porque isso está estreitamente relacionado às necessidades individuais e coletivas.
\end{abstract}

Palavras-chave: Processos de desenvolvimento. Níveis de consciência. Pandemia/Póspandemia. Ecologia profunda. Turismo sustentável.

\section{Summary:}

The need of travelers will change significantly, as will the offers of travel destination providers after the pandemic.

But which evaluation tools should we use if we cannot yet predict where the market will go?

Can a look at the cultural and individual understanding of cyclical development processes help us to master the challenges of post-pandemic tourism and to find solutions?

In this article, I compare the history of the development of the individual, culture, and tourism to predict where post-pandemic tourism can develop.

If we understand how individuals and collectives develop, what needs, fears, challenges, and goals have, we can also predict tourism development, because this is closely linked to individual and collective needs.

Keywords: development processes. levels of consciousness. Pandemic/Postpandemic. Deep ecology. Sustainable tourism.

\section{${ }^{1}$ Psicoterapeuta}




\section{Resumen:}

La necesidad de los viajeros cambiarán significativamente, al igual que las ofertas de los proveedores de destinos de viaje después de la pandemia.

Pero, ¿qué herramientas de evaluación debemos usar si aún no podemos predecir hacia dónde irá el mercado?

¿Puede una mirada a la comprensión cultural e individual de los procesos de desarrollo y los niveles de conciencia ayudarnos a dominar los desafíos del turismo pospandémico y a encontrar soluciones?

En este artículo comparo la historia del desarrollo del individuo, la cultura y el turismo para hacer una predicción de dónde puede desarrollarse el turismo postpandémico.

Si entendemos cómo se desarrollan los individuos y los colectivos, qué necesidades, miedos, desafíos y objetivos tienen, también podemos predecir el desarrollo del turismo, porque esto está estrechamente relacionado con las necesidades individuales y colectivas.

Palabras Claves: procesos de desarrollo. niveles de consciência. Pandemia/Postpandemia. Ecología profunda. Turismo sostenible.

\section{„Solo podemos vivir nuestra vida hacia adelante, pero solo entenderla al revés. “}

Søren Aabye Kierkegaard, dänischer Philosoph

\section{Introducción}

Desde Agustín, maestro de la iglesia numidiana y, más recientemente, obispo de Hipona, que se ocupó de los diferentes niveles de conciencia en el siglo IV d. C., un gran número de investigadores han abordado este tema y desarrollado diferentes teorías. Pensadores modernos como Jean Piaget, Jan Gebser, James Fowler, Laurence Kohlberg, Eric Erikson, Ken Wilber, Bill Plotkin y finalmente Clare W. Graves examinaron las diferentes etapas de la maduración humana. Pero también en las cosmovisiones de las culturas antiguas, como las de los incas, que representaban las diferentes estaciones de maduración en el Chakana ${ }^{2}$, la grabación estructurada de los niveles humanos de conciencia era importante. En la ciencia humana cristiana, por ejemplo, el sacerdote franciscano Richard Rohr y el pastor luterano Andreas Ebert fueron los garantes del éxito que llevó el Eneagrama a aproximadamente 500,000 personas con sus libros en la década de 1980, Carl Gustav Jung descubrió los arquetipos y hoy los psicólogos trabajan con los Myers-Briggs. -Indicador de tipo o el esquema DISG para capturar tipos de personalidad humana.

Clare W. Graves, profesora estadounidense de psicología, fundó la teoría de la existencia cíclica. Con el método psicométrico que desarrolló, estableció una conexión fundamental en la década de 1960:

\footnotetext{
${ }^{2}$ Carlos Milla Génesis de la Cultura Andina
} 
Cadernos CERU, Série 2, Vol. 31, n. 1, jun. 2020

Cierta cultura encaja con ciertos valores. La cultura líder está cambiando en consecuencia las familias, grupos, tribus, sociedades y también compañías.

En estas niveles hay un intercambio constante entre un cierto conjunto de condiciones ambientales y un organismo social que se enfrenta a él.

Este organismo necesita mecanismos de afrontamiento adecuadamente maduros (emocionales, físicos, intelectuales) que lo ayuden a hacer frente a este entorno.

Por ejemplo, examinamos a un niño que ingresa a la escuela para mostrar los mecanismos de afrontamiento apropiados. Para poder orientarse en el nivel de existencia correspondiente, debe poder expresarse lingüísticamente y también tener habilidades motoras finas para aprender a escribir. Para esto necesitas bolígrafos, cuadernos y libros. Debe ser capaz de aceptar reglas y haber aprendido el comportamiento social. Y necesita maestros, para enseñar y una sala para aprender.

Cada cambio de un nivel al siguiente ocurre como una estrategia de supervivencia evolutiva, sin la cual la especie humana no habría sobrevivido.

Nuevos valores y nuevos hábitos se desarrollan durante un proceso dinámico de adaptación a un entorno cambiante. No sientes este cambio cuando estás justo en el medio. Solo en retrospectiva puedes ver que se ha desarrollado una nueva forma de conciencia, con una mezcla individual de formas de pensar y visiones del mundo. Los valores, los sistemas de creencias, los principios organizativos y los estilos de vida ahora diferirán claramente de los de los demás. Estas nuevas posibilidades de percepción y comprensión están permanentemente disponibles para el individuo una vez que han alcanzado un nuevo nivel.

Utilizando el ejemplo de un idioma, se puede determinar que cualquier persona que haya aprendido a hablar también tendrá acceso a esta forma de comunicación en el futuro. Puede usar el nivel que ha aprendido, pero también tiene la oportunidad de ampliar su comprensión del lenguaje. Esto también cambia la complejidad de su pensamiento. Podrá comunicarse de una manera más diferenciada y, por lo tanto, adoptar nuevas etapas de desarrollo.

Si examinamos los niveles de conciencia de las sociedades, podemos ver que no todos los miembros ya tienen esta conciencia. Todos los niveles estarán representados debajo y posiblemente también algunos por encima del nivel de conciencia de la sociedad examinada. Sin embargo, se puede suponer que la sociedad tiene los valores, la moral, los modales, el comportamiento social y las formas organizativas típicas de su nivel. Estos dominan la vida pública y privada dentro de la sociedad.

En este artículo, quisiera construir un puente entre el desarrollo de las personas, las culturas y su sociedad, así como el tipo de viaje, para encontrar una solución que nos pueda 
Cadernos CERU, Série 2, Vol. 31, n. 1, jun. 2020

ayudar con los desafíos del turismo pospandémico. Antes de presentar las etapas individuales, me gustaría dar una descripción tabular de mis parámetros de observación:

\section{La conexión entre individuo, colectivo, sociedad y turismo}

\begin{tabular}{|c|c|c|c|c|}
\hline $\begin{array}{l}\text { Nivel } \\
\text { es de } \\
\text { conciencia }\end{array}$ & Individu & colectivo/socie & $\begin{array}{l}\text { turis } \\
\text { mo historico }\end{array}$ & $\begin{array}{ll} & \text { turismo } \\
\text { actual }\end{array}$ \\
\hline 1 & $\begin{array}{l}\text { "Existo" } \\
\text { Sobreviv } \\
\text { o de } r \text { forma } \\
\text { adversa, bajo } \\
\text { ataques } \\
\text { y hostiles } \\
\text { vulnerabilidad a } \\
\text { mi con } \\
\text { cuerpo. }\end{array}$ & $\begin{array}{l}\text { Transición al } \\
\text { ser humano } \\
\text { Nivel arcaico } \\
\text { de voluntad para } \\
\text { sobrevivir }\end{array}$ & $\begin{array}{l}\text { razon } \\
\text { es prácticas } \\
\text { como la } \\
\text { búsqueda de } \\
\text { comida o } \\
\text { agua } \\
\text { hicieron que } \\
\text { las personas } \\
\text { viajaran }\end{array}$ & \\
\hline 2 & $\begin{array}{l}\text { "Somos } \\
\text { una familia y } \\
\text { nos } \\
\text { mantenemos } \\
\text { unidos" } \\
\qquad \text { Meta: } \\
\text { armonía } \\
\text { armonía, } \\
\text { asegurar } \\
\text { existencia, la } \\
\text { pertenecer }\end{array}$ & $\begin{array}{l}\text { Nivel mágico- } \\
\text { animista de espíritus y } \\
\text { clanes ancestrales. } \\
\text { Culturas } \\
\text { tribales, arte arcaico, } \\
\text { magia. }\end{array}$ & $\begin{array}{l}\text { la } \\
\text { huida de los } \\
\text { desastres } \\
\text { naturales } \\
\text { convirtió a } \\
\text { las personas } \\
\text { en viajeros }\end{array}$ & $\begin{array}{l}\text { Flujos de } \\
\text { refugiados de } \\
\text { zonas de guerra, } \\
\text { migraciones por } \\
\text { razones } \\
\text { existenciales y } \\
\text { humanitarias. }\end{array}$ \\
\hline 3 & $\begin{array}{l}\text { "Peleo" } \\
\text { Soy } \\
\text { poderoso, }\end{array}$ & $\begin{array}{c}\text { Nivel } \\
\text { egocéntrico de los }\end{array}$ & $\begin{array}{l}\text { Las } \\
\text { grandes } \\
\text { guerras y } \\
\text { campañas de }\end{array}$ & $\begin{array}{l}\text { Movimien } \\
\text { tos de tropas, } \\
\text { operaciones } \\
\text { militares, }\end{array}$ \\
\hline
\end{tabular}




\begin{tabular}{|c|c|c|c|c|}
\hline & $\begin{array}{l}\text { luchando por el } \\
\text { respeto y para } \\
\text { mi ventaja para } \\
\text { evitar } r \text { la } \\
\text { vergüenza y la } \\
\text { culpa }\end{array}$ & $\begin{array}{l}\text { dioses del poder y los } \\
\text { luchadores. } \\
\text { Tropas, } \\
\text { conquistas, reinos }\end{array}$ & $\begin{array}{l}\text { Odiseo, } \\
\text { Alejandro } \\
\text { Magno, } \\
\text { Atila, } \\
\text { conquistador } \\
\text { español y } \\
\text { exilio } \\
\text { europeo que } \\
\text { emigró a } \\
\text { América del } \\
\text { Norte. }\end{array}$ & $\begin{array}{l}\text { operaciones de } \\
\text { mantenimiento de } \\
\text { la paz y } \\
\text { observadores de } \\
\text { las Naciones } \\
\text { Unidas, viajes de } \\
\text { campo, } \\
\text { excavaciones, } \\
\text { expediciones y } \\
\text { operaciones } \\
\text { espaciales. }\end{array}$ \\
\hline 4 & $\begin{array}{l}\text { "Somos } \\
\text { los verdaderos } \\
\text { creyentes" } \\
\text { lealtad } \\
\text { vinculante, } \\
\text { disciplina, roles } \\
\text { y } \\
\text { responsabilidad } \\
\text { es fijos, } \\
\text { sumisión a un } \\
\text { principio de } \\
\text { orden, visión del } \\
\text { mundo estable, } \\
\text { valores fijos, la } \\
\text { única verdad }\end{array}$ & $\begin{array}{l}\text { Nivel absoluto } \\
\text { de verdad y valores. } \\
\text { Estados, } \\
\text { monoteísmo }\end{array}$ & $\begin{array}{l}\text { Viaje } \\
\mathrm{s} \quad \text { de } \\
\text { peregrinació } \\
\mathrm{n}, \text { comercio } \\
\text { de } r \text { larga } \\
\text { distancia. }\end{array}$ & $\begin{array}{l}\text { El turismo } \\
\text { de masas, el } \\
\text { turismo como } \\
\text { monocultivo, la } \\
\text { industria del } \\
\text { entretenimiento, } \\
\text { las idiosincrasias } \\
\text { culturales de los } \\
\text { países se retrasan, } \\
\text { el extranjero se } \\
\text { adapta a los } \\
\text { deseos de los } \\
\text { huéspedes y a los } \\
\text { requisitos del } \\
\text { operador } \\
\text { turístico, creando } \\
\text { así un telón de } \\
\text { fondo, un daño } \\
\text { enorme para el } \\
\text { medio ambiente y }\end{array}$ \\
\hline
\end{tabular}




\begin{tabular}{|c|c|c|c|c|}
\hline & & & & $\begin{array}{l}\text { la naturaleza, } \\
\text { daños climáticos } \\
\text { debido a medios } \\
\text { de transporte } \\
\text { intensivos en } \\
\text { emisiones, } \\
\text { eliminación de } \\
\text { residuos, mayor } \\
\text { consumo de } \\
\text { productos } \\
\text { naturales. } \\
\text { Recursos } \\
\text { Contaminación } \\
\text { del agua y del } \\
\text { suelo, aumento } \\
\text { del consumo de } \\
\text { energía, deterioro } \\
\text { de biotopos y } \\
\text { ecosistemas, } \\
\text { desfiguración } \\
\text { estética } \\
\text { paisajes naturales } \\
\text { y culturales } \\
\text { cultivados } \\
\text { través } \\
\text { infraestructuras } \\
\text { turísticas }\end{array}$ \\
\hline 5 & $\begin{array}{l}\text { "¡Quiero } \\
\text { ser libre!" } \\
\qquad \begin{array}{lr}\text { El } \\
\text { objetivo } \\
\text { garantizar } \quad \text { la }\end{array}\end{array}$ & $\begin{array}{l}\text { Nivel racional } \\
\text { de esfuerzo e } \\
\text { investigación. }\end{array}$ & $\begin{array}{l}\text { Viaja } \\
\text { r en colonias } \\
\text { para } \\
\text { fortalecer las } \\
\text { relaciones } \\
\text { económicas }\end{array}$ & $\begin{array}{l}\text { Viajes de } \\
\text { larga distancia y } \\
\text { turismo de } \\
\text { aventura como un } \\
\text { paquete, viajes en } \\
\text { crucero. Las }\end{array}$ \\
\hline
\end{tabular}




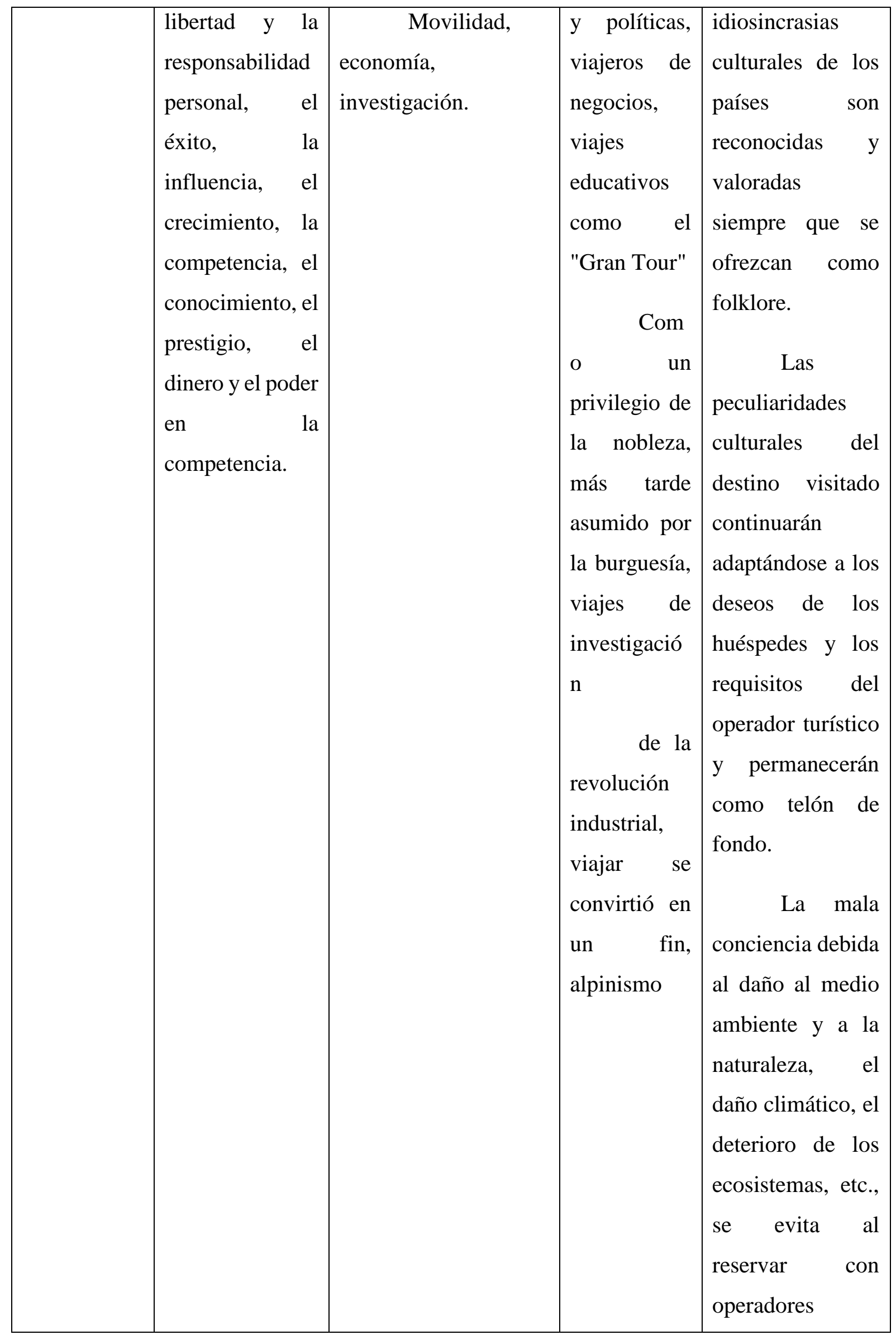




\begin{tabular}{|c|c|c|c|}
\hline & & & $\begin{array}{l}\text { turísticos que } \\
\text { prometen } \\
\text { sostenibilidad. } \\
\text { Sin embargo, no } \\
\text { lo verificas. }\end{array}$ \\
\hline 6 & 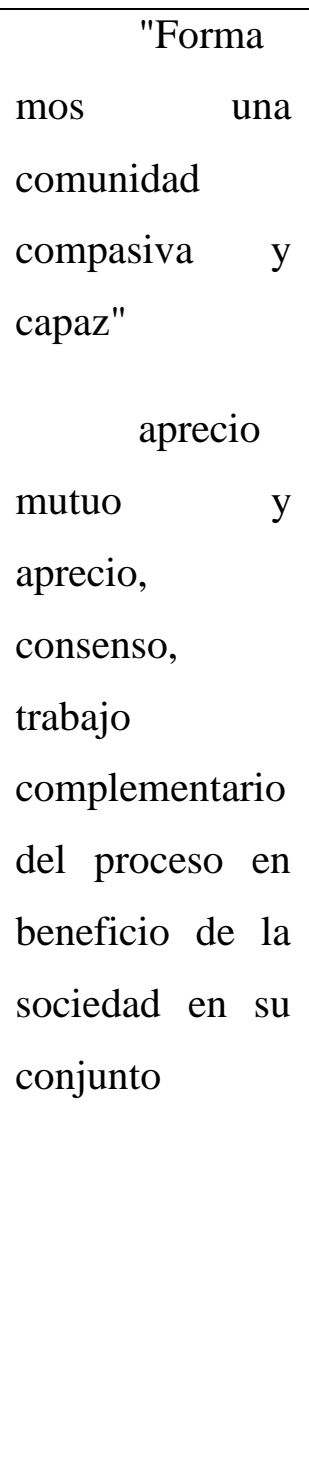 & $\begin{array}{l}\text { Nivel } \\
\text { relativista de } \\
\text { responsabilidad } \\
\text { social. } \\
\qquad \text { Derechos } \\
\text { humanos, } \\
\text { colectivismo, medio } \\
\text { ambiente. }\end{array}$ & \begin{tabular}{l} 
turismo \\
suave y sostenible \\
\multicolumn{1}{c}{ viajes } \\
ambiental y \\
socialmente \\
responsables, \\
$\qquad$ uso \\
sostenible de los \\
destinos \\
turísticos, respeto \\
por \\
tradiciones \\
culturales de los \\
países visitados, \\
uso \\
cuidadoso de los \\
recursos \\
naturales, \\
ecoturismo
\end{tabular} \\
\hline 7 & $\begin{array}{l}\text { "Me } \\
\text { expreso" }^{\text {con la }} \\
\text { mayor libertad y } \\
\text { responsabilidad } \\
\text { personal }\end{array}$ & \begin{tabular}{lr}
\multicolumn{2}{c}{ Nivel } \\
sistémicamente \\
integrador \\
inclusión de \\
perspectiva de \\
los niveles.
\end{tabular} & $\begin{array}{l}\text { Nómadas } \\
\text { digitales, viajeros } \\
\text { individuales que } \\
\text { buscan contacto } \\
\text { con los residentes } \\
\text { del destino de } \\
\text { viaje y no se ven a }\end{array}$ \\
\hline
\end{tabular}




\begin{tabular}{|c|c|c|c|}
\hline & 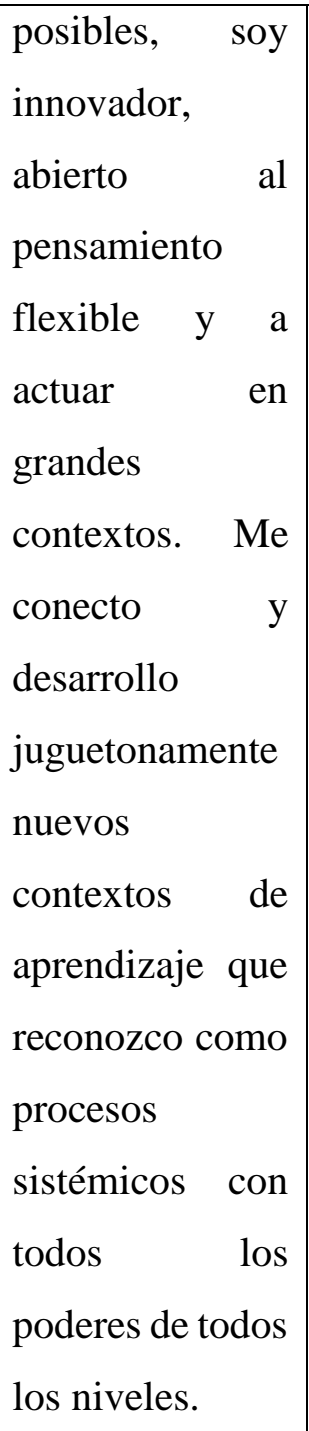 & $\begin{array}{l}\text { Complejidad, } \\
\text { caos, } \\
\text { interdependencia. }\end{array}$ & $\begin{array}{l}\text { sí mismos como } \\
\text { turistas, sino } \\
\text { como parte de una } \\
\text { comunidad global } \\
\text { inmersa en la } \\
\text { cultura del } \\
\text { destino de viaje. }\end{array}$ \\
\hline 8 & $\begin{array}{l}\text { "Servim } \\
\text { os al ser mismo } \\
\text { y, por lo tanto, a } \\
\text { la supervivencia } \\
\text { de toda la } \\
\text { humanidad". } \\
\text { Compasión } \\
\text { global, } \\
\text { orientación } \\
\text { sensorial: } \\
\text { implantar } \\
\text { promover } \\
\text { valores éticos }\end{array}$ & \begin{tabular}{l}
\multicolumn{2}{c}{ Nivel integral } \\
holístico de \\
globales
\end{tabular} & \\
\hline
\end{tabular}




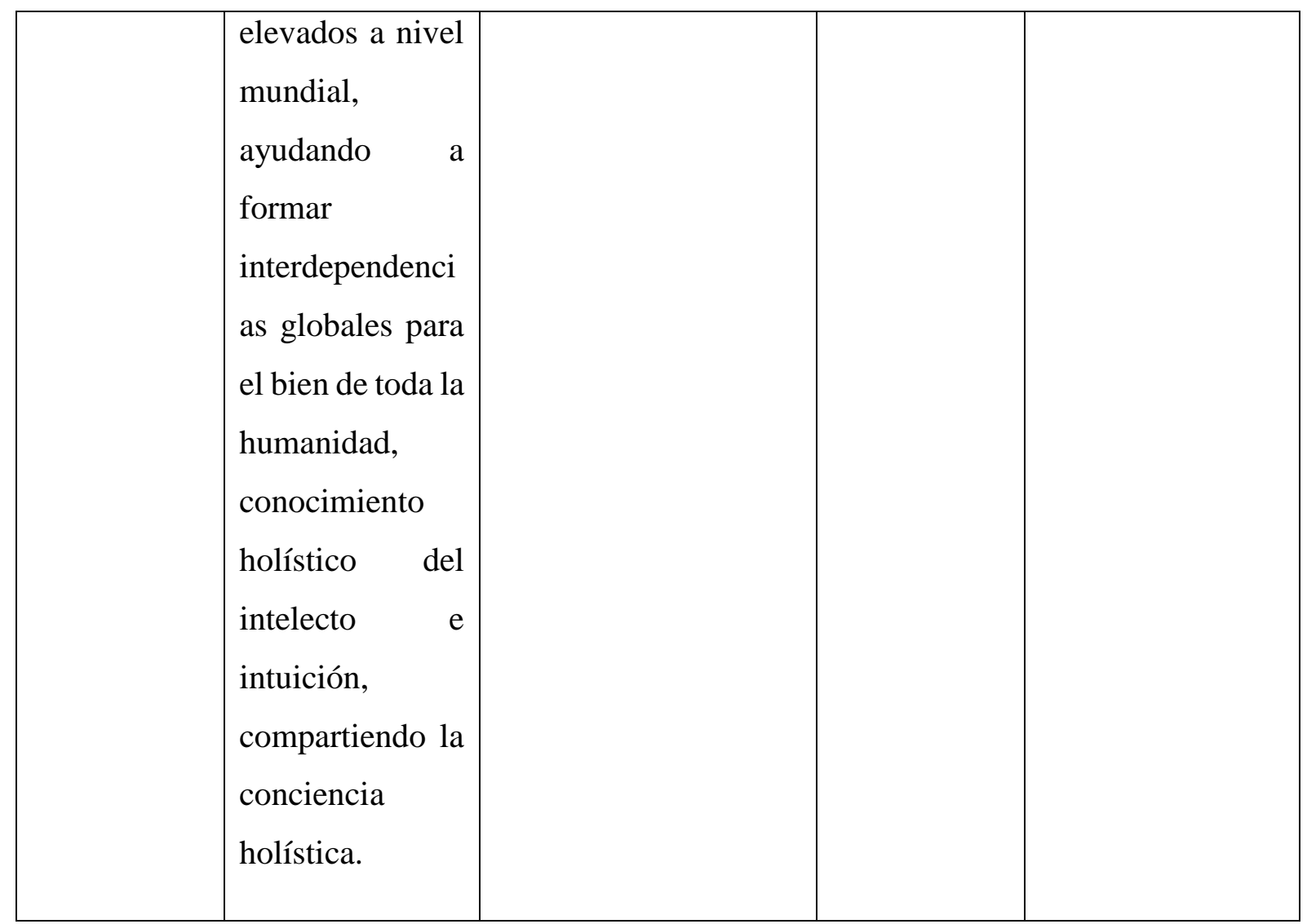

Tabelle Graves/Brummer

\section{Cómo surgen las etapas de desarrollo}

La evolución de un nuevo nivel de conciencia ocurre en tiempos de crisis, si las estrategias y normas anteriores ya no pueden resolver los problemas actuales o si ocurren otras condiciones de vida. Si el entorno cambia drásticamente, también se deben desarrollar nuevos valores y habilidades. En última instancia, cada nivel de conciencia es un intento de resolver eso en el curso nuestra evolución tiene que ser reemplazada una y otra vez por intentos aún mejores de resolverla.

Para que surjan niveles más altos de civilización, los niveles anteriores deben funcionar de manera confiable. Por lo tanto, es una tarea importante honrar, cultivar y consolidar los méritos duraderos de los niveles anteriores para que la transición a niveles superiores sea posible de manera sostenible. De esta manera, todas las etapas juntas forman una corriente viva de complejidad cambiante en la que nos movemos hacia arriba y hacia abajo.

\section{Cada individuo repite la historia humana en su desarrollo}

Lo que se aplica al desarrollo de tribus, pueblos, culturas y sociedades también se aplica al desarrollo de cada persona. Un niño puede hacer hoy en unos pocos años lo que ha llevado miles de años en la historia humana. Después de nacer, pasamos por la historia evolutiva de la 
Cadernos CERU, Série 2, Vol. 31, n. 1, jun. 2020

conciencia humana en el orden histórico exacto. Este fue uno de los descubrimientos cruciales de Grave. Es esencial caminar a través de cada paso, ningún paso puede ser despreciado u omitido.

\section{IV. los niveles}

\section{IV.1. nivel 1 - instinto y supervivencia}

\section{IV.1.1 el individuo}

Inicialmente, cada bebé es un cuerpo (ein „Körperselbst “), que fue arrojado a un mundo en el que nunca podría sobrevivir por sí solo. Está completamente indefenso y las principales prioridades son alimentos, agua, calor y seguridad. El recién nacido no puede diferenciar entre sí mismo y el mundo, ni siquiera entre él y la madre, y vive en completa autosuficiencia. Si una persona no tiene éxito en el proceso de separación de esta fase simbiótica, no puede establecer límites emocionales claros más tarde entre su propio ser y el de los demás. Su mayor temor es morir si las fuerzas vitales externas deciden en su contra.

\section{V.1.2 cultura y sociedad}

La transición de animales a humanos data de hace unos 100.000 años.

En esta época se trataba de la supervivencia desnuda del individuo. El hombre vive en el "ahora" eterno, un presente intemporal, puro, una existencia onírica que no conoce sistemas sociales, ni tribus organizadas ni clanes. Vive en pequeños clanes y hordas desestructuradas que le ofrecen protección y calidez. Sus hábitos y comportamiento instintivo le sirven para sobrevivir. Todavía no puede pensar de manera compleja y, por lo tanto, no puede planificar. Su pensamiento es prelógico y presocial. No puede ponerse en el lugar de otra persona. Las personas en este nivel de conciencia no pueden diferenciar entre ellas y la naturaleza. Son la naturaleza, simplemente existen, al igual que las plantas, los animales, las montañas o los ríos.

Aquí se encuentran las habilidades ocultas de todos los sentidos, desde la intuición hasta el "séptimo sentido". La telepatía y la clarividencia parecen ser más pronunciadas en esta etapa que en las personas que viven en un entorno técnico en etapas posteriores. Este ser no simplemente ha desaparecido de las personas que viven en niveles superiores de conciencia. Permanece como base y se activa cuando los disparadores nos permiten retroceder. Todavía sentimos este nivel hoy cuando hay peligro para la vida, enfermedades, depresión, víctimas de tortura, suicidio, en campos de prisioneros de guerra, campos de refugiados, terror psicológico, terremotos, tsunamis, desastres naturales traumáticos, un choque después de un accidente de tráfico, un trauma por bomba, el genocidio y daño cerebral orgánico como la demencia. 


\section{V.1.3 turismo historico}

Razones prácticas como la búsqueda de comida o agua hicieron que las personas viajaran. Se trataba de asegurar su supervivencia.

\section{V.2. nivel 2 - mago y clan}

\section{V.2.1 el individuo}

La edad mágica es la época de los cuentos de hadas, duendes y hadas. Es el final de la infancia simbiótica. El niño se siente físicamente separado de su madre, se para sobre sus propios pies, habla las primeras palabras. Sin embargo, esta separación aún no se ha hecho mentalmente. Por lo tanto, su entorno sigue siendo "animista". Puede hablar con su peluche, una silla es mala si chocas con ella, amigos invisibles lo acompañan. Surge un sentimiento de control e interacción confiable con el mundo invisible de lo sobrenatural.

\section{V.2.2 cultura y sociedad}

La cultura ciclica emerge

Culturalmente, asignaría a este largo nivel de desarrollo humano al del matriarcado. Hay una gran diosa que da vida y quita la vida. La gran madre que da a luz a todo en su regazo, que alimenta a sus hijos, a veces se enoja y a veces envía plagas cuando no eres "buena".

Los cambios climáticos violentos obligaron a las personas a obtener alimentos de una nueva manera. Estos nuevos desafíos solo podrían resolverse uniéndose a grupos. Así surgieron clanes y tribus hace unos 50.000 años para asegurar la supervivencia. No hay propiedades privadas en estos. En las culturas del segundo nivel de conciencia, la corrupción y el nepotismo no son moralmente deshonrosos, sino incluso necesarios. Si tienes algo, debes compartirlo con tus familiares, de lo contrario serás culpable dentro del clan. El individualismo no tiene lugar en este nivel.

Una sola vida no cuenta mucho más allá del bienestar del grupo. El hombre comienza a diferir de los demás, pero su alma pertenece a un alma grupal común. El sacrificio humano y la sangre vengativa son comunes; El sacrificio propio garantiza la supervivencia de la familia. La exclusión del grupo o la familia es la mayor amenaza para protegerse. Los miembros de otras tribus son, en principio, una amenaza, solo aquellos que pertenecen a su propio grupo se consideran humanos.

Todo sigue un conjunto fijo de reglas que viene "de lo viejo" y no se cuestiona: iniciación, publicidad nupcial, bodas, entierros, artesanías: toda la vida está incrustada en ritos. Como todavía no hay un guión, el conocimiento almacenado en la tribu y el clan es transmitido oralmente por los ancianos. Se considera un tesoro valioso y se transmite de generación en generación. En esta fase, surgen los mitos de la creación. 
Cadernos CERU, Série 2, Vol. 31, n. 1, jun. 2020

Se estima que alrededor del 10\% de la población mundial vive principalmente en este nivel. (La Amazonia, Papua Nueva Guinea y también en el entorno rural de algunos países en desarrollo y emergentes).

La organización del Allyu en las comunidades quechua y aymara sigue siendo un punto central del sistema social. El término ayllu, que se traduce del quechua como "familia, familia extensa, comunidad de aldeas", describe en su significado básico la unidad política más baja de la sociedad andina tradicional. Es una comunidad de ascendencia y parentesco, así como la comunidad cooperativa organizada de la aldea como comunidad local. La propiedad de la tierra se comparte y se gestiona en forma de minka o se redistribuye cada año como un "préstamo". Pero un ayllu también tiene aspectos religiosos que le dan significado porque cada ayllu tiene, además de las deidades generales de los Andes, su propia deidad local, su "wak'a".

El sello distintivo de este nivel de conciencia es el círculo.

Las aldeas, las cabañas y los lugares de culto están dispuestos en círculo, se baila en círculo, se sientan en círculos, imaginas el mundo como un disco redondo, porque el cielo toca la tierra en todas las direcciones. El tiempo no es una flecha que va del pasado a través del presente y hacia el futuro, sino un ciclo eterno, incrustado en el día y la noche, las estaciones, las semillas y las cosechas. El sol determina el curso del año, la luna el ciclo de las mujeres.

Todo lo que expresa nuestros lazos familiares tiene sus raíces en el segundo nivel. También insignias con las que se te puede ver pertenecer a un grupo, como una camiseta de fanático, el uso de emblemas o colores del club, las botas de salto - todas estas son señales de creación de identidad que diferencian al "nosotros" de los "otros".

\section{V.2.3. turismo}

\section{V.2.3.1. turismo historico}

En esta era, razones prácticas como huir de los desastres naturales hicieron que las personas viajaran, luego, que se establecieran en territorios determindos y posteriormente el que también recibieran visitas.

\section{V.2.3.2. turismo actual}

Se producen flujos de refugiados de zonas de Guerra y migraciones por razones existenciales y humanitarias.

\section{V.3 nivel 3 - Guerreros y conquistadores}

\section{V.3.1. el indviduo}

En esta etapa, el individuo se libera de la integración mágica en el grupo o la familia. Los niños desarrollan las primeras estructuras del ego en la "fase de desafío". La palabra "no" es una de las palabras más importantes en este momento. El niño se convierte en el ombligo del 
Cadernos CERU, Série 2, Vol. 31, n. 1, jun. 2020

mundo. Todo lo que descubre y experimenta se relaciona con él. En esta fase, el niño prueba si las instrucciones y prohibiciones de los padres realmente se aplican. Ahora se necesitan límites, de lo contrario se convertirá en un tirano que gobierna a toda la familia. Piensa y actúa egocéntricamente, manipulativa e impulsivamente. Su credo: "¿Lo quiero y lo quiero ahora!"

En la pubertad vuelves a una especie de segunda fase de rebelión. Uno se defiende de la seducción, la dependencia y la opresión. Desarrollas una audaz confianza en ti mismo y una fuerza egoísta provocativa. Aprende a salir de la asociación familiar para vivir como individuos independientes, hacia la autoafirmación y una autoconciencia saludable, perseverancia e independencia. La energía, la agresión, la ira y la sed de aventuras ayudan a liberarse valientemente de las rígidas tradiciones.

\section{V.3.2 cultura y sociedad - el fin del matriarcado, el comienzo del patriarcado, feudalismo}

Hace unos 10.000 años, las condiciones de vida cambiaron nuevamente. Nuevamente, los cambios climáticos están causando las necesidades existenciales de los clanes. Las primeras personas valientes se propusieron atraer nuevos horizontes. Vienen en áreas que ya están pobladas por otras personas.

Comienzan las batallas territoriales.

El tercer nivel significa lucha. Corresponde al arquetipo de guerreros, amazonas y héroes. No conocen límites y no los aceptan cuando se topan con uno. Saquean, violan y asesinan sin control. Uno lucha sin dudar con fuerza bruta, mentiras y trampas, es astuto y sin remordimientos. La fuerza prevalece y somete a los demás. El joven héroe piensa que es inmortal, como hoy, los jóvenes en sus autos sintonizados, conducen carreras prohibidas, organizan fiestas en Komasauf o prueban sus límites tomando drogas.

Surge el feudalismo. Surgen los Estados y los primeros pequeños reinos.

El tercer nivel no tiene en cuenta las convenciones y puede allanar el camino para nuevos modelos de vida y relación con visión de futuro. Por ejemplo, las pioneras del feminismo resistieron amargamente, dándonos acceso al sistema educativo y el derecho al voto.

Las naciones con una alta proporción de jóvenes naturalmente albergan una gran cantidad de energía de tercer nivel en su población. Los partidos políticamente agresivos u organizaciones clandestinas son muy populares en estos países. La mafia y los grupos terroristas también son organizaciones en este nivel de conciencia. Los señores de la guerra en Somalia, IRA en Irlanda del Norte, ETA en el País Vasco son ejemplos de estas organizaciones revolucionarias e insurgentes. Siempre involucrado en rivalidades en el interior; externamente esparcen el miedo a través de la fuerza bruta. 


\section{V.3.3 turismo}

\section{V.3.3.1 turismo historico}

Hay guerras y cruzadas. Odiseo y el Caballo de Troya, Alejandro Magno, que se mudó de Macedonia a la India y fundó un gran imperio, Atila y los hunos, Genghis Khan y los mongoles, los conquistadores españoles en América Central y del Sur, los exiliados europeos en América del Norte, el bisonte y exterminó a los pueblos originarios.

Pero la curiosidad y la sed de investigación también son parte de la tercera etapa. Los viajeros como James Cook, el explorador africano David Livingstone o Roald Amundsen y Robert Scott (1911) representan las cualidades positivas de este nivel.

\section{V.3.3.2 turismo actual}

Existen movimientos de tropas, operaciones militares, operaciones de mantenimiento de la paz y observadores de las Naciones Unidas, viajes de campo, excavaciones, expediciones y operaciones espaciales.

\section{V.4. nivel 4 - orden y estructura}

\section{V.4.1. el individuo}

Las personas aprenden a seguir reglas vinculantes y a adherirse a las estructuras. Altruismo, compartir, dar y recibir equilibrado, camaradería, "uno para todos, todos para uno". La egocentricidad narcisista impulsivamente agresiva debe dar paso al sentimiento ético por las consecuencias de sus acciones. Pensar es convencional y concreto. Uno polariza: quien no nos pertenece está en contra de nosotros. La identidad se gana a través del colectivo: la familia, la comunidad del pueblo, la gente, la iglesia. Vestido y uniforme de ayuda otorgan identidad y pertenencia. El comportamiento adecuado y el cumplimiento de la etiqueta es importante. El miedo a ser excluido del grupo pone el foco en las necesidades de los demás. Uno es útil y amigable, presta atención a lo que piensan los demás y se basa en las autoridades. La obediencia, la culpa y la vergüenza surgen. Se desarrollen virtudes como la puntualidad, el orden, la diligencia y la cortesía.

\section{V.4.2 cultura y sociedad}

El enfoque cambia de egocentricidad a etnocentricidad. Con este nivel aterrizamos en la presencia y conciencia de numerosas personas en este planeta. Alrededor del $50 \%$ de la población mundial vive en este nivel de conciencia.

El cuarto nivel de conciencia establece límites, define reglas y leyes, crea orden, describe valores y virtudes. Hacen juicios sobre lo correcto y lo incorrecto e imponen sanciones. Así es como surgen las ideas morales, las tradiciones y los reinos. Se crean aparatos oficiales 
Cadernos CERU, Série 2, Vol. 31, n. 1, jun. 2020

que solo pueden administrarse si los funcionarios públicos también pueden leer, escribir y hacer operaciones aritméticas. Por lo tanto, el desarrollo de la escritura era necesario.

El mundo está bien organizado en cajas, normas DIN, insignias de rango, cámaras de artesanías, aparatos judiciales, horarios y jerarquías. Hay reglas y regulaciones exactas y consecuencias claras si las ignora. El sistema de valores es blanco y negro, los matices son sospechosos.

Los alcohólicos anónimos luchan contra la adicción al demonio de la tercera etapa con la estructura estricta de sus reuniones y una secuencia clara de sus doce pasos de la cuarta etapa.

Las grandes religiones monoteístas mundiales emergen e integran al individuo en el gran todo absoluto. Incluso el rey, que ya no puede ser el soberano soberano. Por lo tanto, deriva su legitimación de un dios. Incluso Carlomagno se describió a sí mismo como el "Emperador por la gracia de Dios". La religión se usa con fines de poder. Hay una vida redentora que recompensa lo moralmente bueno con la vida eterna. Solo los iniciados saben cómo ponerse en contacto con Dios y les paga para obtener indulgencies.

\section{V.4.3 turismo}

\section{V.4.3.1 turismo historico}

En el curso de la política agresiva de conquista y expansión, se abrieron rutas comerciales y comenzó el comercio de larga distancia. Las peregrinaciones religiosas, por ejemplo las peregrinaciones a La Meca, se hicieron cada vez más populares. En España la ruta del Camino de San Santiago, eminentemente religiosa, se tornó en tiempos actuals una importante ruta turística.

\section{V.4.3.2 turismo actual}

El turismo de masas, el turismo como monocultivo, la industria del entretenimiento, las idiosincrasias culturales de los países se retrasan. El extranjero se adapta a los deseos de los huéspedes y a los requisitos del operador turístico, creando así un telón de fondo, un daño enorme para el medio ambiente y la naturaleza, daños climáticos debido a medios de transporte intensivos en emisiones, eliminación de residuos y el mayor consumo de productos naturales. En relación a los recursos naturales la contaminación del agua y del suelo, el aumento del consumo de energía, el deterioro de biotopos y ecosistemas, la desfiguración estética de paisajes naturales y culturales cultivados a través de infraestructuras turísticas van en aumento.

\section{V.5 nivel 5 - emprendimiento maduro y éxito}

\section{V.5.1. el individuo}

„sapere aude “- ten el coraje de usar tu propia comprensión

Immanuel Kant 
Las personas se convierten en adultos sensibles que son emocional y financieramente independientes y responsables. Desarrolla la autoconciencia interna, sopesa los argumentos con sensatez, puede pensar racional y dialécticamente y puede abrir además independientemente campos de conocimiento. Como regla general, vive de una manera orientada hacia el futuro, cree en el progreso y la educación permanente, y da forma y administra su vida de manera eficiente.

Como una persona con orientación científica, solo acepta números, datos y hechos específicos, se informa mediante estadísticas, análisis y hace pronósticos. Él corrobora sus tesis a través de investigaciones de campo y experimentos que son científicamente sólidos y comprensibles. Las personas en este nivel de conciencia han aprendido a pensar de manera independiente, pero aún no se dan cuenta de que sus conceptos son solo construcciones de realidades.

Si el hombre no se ha responsabilizado por sus acciones, ahora está buscando al culpable. Es la víctima inocente de circunstancias difíciles, el hogar, la sociedad, el consumo, los medios de comunicación o el frío social. Existe un gran peligro de que una persona del quinto nivel de conciencia pierda una visión clara de la responsabilidad personal y la autonomía. Esto lo convierte en un caso de atención que debe ser protegido, apoyado financieramente y tratado terapéuticamente para que pueda sobrevivir en la sociedad.

\section{V.5.2 cultura y sociedad}

Una nueva conciencia se desarrolló durante la época de la Ilustración hasta los tiempos modernos:

El ciudadano maduro, autoconsciente, investigador y cuestionador.

Antes de eso, si la sociedad se enfocaba en el más allá, ahora comienza a enfocarse en lo concreto aquí y ahora en su investigación. El comienzo de este período esclarecedor reside en el Renacimiento, que promueve el arte y la ciencia. Los pintores representan el mundo tal como la gente lo ve subjetivamente. A través del dibujo en perspectiva. La naturaleza muerta y la pintura de paisajes abren espacios virtuales. La observación precisa de la naturaleza ahora determina el arte.

La Reforma de Martín Lutero establece el curso. Ya nadie tiene que creer en Dios, porque ahora la ciencia se ocupa de la interpretación del mundo. Usted cuestiona los "hechos" dados y busca las causas y los fundamentos del mundo.

La gente quiere abrirse y medir el mundo entero. Cartografía con sed de conocimiento, construcción de dispositivos de rayos $\mathrm{X}$, dispositivos de ultrasonido y escáneres cerebrales, radiotelescopios y satélites espaciales, lo que desencanta la naturaleza. La naturaleza ahora 
Cadernos CERU, Série 2, Vol. 31, n. 1, jun. 2020

inanimada se define como una materia prima. Ya no es la madre viva, sino la materia pura que puede ser explotada sin piedad. Se ensucia y destruye. Las personas destruyen su medio de vida con pesticidas y fertilizantes artificiales, pero el cuarto nivel actúa sin principios ni moral. La competencia, el crecimiento y el éxito solo cuentan. Los resultados a corto plazo son más importantes. Los recursos de la naturaleza se explotan allí donde hay una ganancia esperada, pero los humanos también degeneran en "capital humano".

Los Estados modernos, el sistema financiero y las industrias se están formando. Nace el capitalismo.

Surge un nuevo arquetipo: el desarrollo adicional altamente eficiente del mago y el guerrero a un pionero espiritual. Ejemplos de esto son Alexander von Humboldt, Isaac Newton, Gottlieb Daimler, Thomas Alva Edison, Werner von Siemens

La era del ateísmo ha comenzado. "Dios está muerto" postula Friedrich Nitzsche y Dios está ahora en el sofá y está siendo analizado a fondo por el psicoanalista. Sin embargo, el pensamiento racional sin una creencia crea un vacío espiritual interior. Y así, los jóvenes alimentan su anhelo de mitos durante horas con literatura fantástica y juegos de computadora para experimentar épicas de héroes marciales en batallas de los últimos tiempos en la realidad virtual. Puede ser económicamente exitoso, pero también es un perdedor porque ha perdido su propio mito.

\section{V.5.3 turismo}

\section{V.5.3.1 turismo historico}

El descubrimiento y la conquista del "Nuevo Mundo"

El viajar en colonias para fortalecer las relaciones económicas y políticas, viajeros de negocios, el "Grand Tour" - viajes educativos como un privilegio de la nobleza, más tarde asumido por la burguesía, viajes de investigación. Con la revolución industrial, viajar se convirtió en un fin. Surgen el alpinismo y el movimiento relacionado con el romance natural.

\section{V.5.3.2 turismo actual}

Viajes de larga distancia y turismo de aventura como un paquete y viajes en crucero.

Las peculiaridades culturales de los países son reconocidas y valoradas siempre que no perturben las vacaciones y se ofrezcan como entretenimiento folclórico. Los aspectos culturales del destino visitado continuarán adaptándose a los deseos de los huéspedes y los requisitos del operador turístico y seguirán siendo el telón de fondo. La conciencia culpable debido al daño al medio ambiente y la naturaleza, el daño climático, el deterioro de los ecosistemas, etc., se intenta evitar al reservar con operadores turísticos que prometen sostenibilidad. Sin embargo, esto no se verifica más con indicadores sostenibles. 
Cadernos CERU, Série 2, Vol. 31, n. 1, jun. 2020

\section{V.6 nivel 6 - la civilización empática ${ }^{3}$}

\section{V.6.1. el individuo}

¿Quién soy? es la pregunta global que plantea un ser humano en el sexto nivel.

Quiere explorar su vida interior, se observa intensamente y, por lo tanto, reconoce su condicionamiento a través de su origen, cultura, socialización y género. Se da cuenta de cuán alejado y perdido está y cómo sus sentimientos subjetivos influyen en la percepción de su realidad. Se da cuenta de que está construyendo e interpretando su realidad. Entonces comienza a buscar la integración de diferentes personalidades. Es pacífico y sensible, simpatiza con su entorno y cambia su enfoque a la igualdad de oportunidades en lugar de pensar en competitividad y rendimiento.

\section{V.6.2 cultura y sociedad}

\section{,all you need is love “}

the Beatles

La civilización empática se da a luz a sí misma.

Surgen el movimiento de la generación del poder de las flores, el pacifismo y el primer movimiento ecológico. Los municipios se fundan porque después de las guerras mundiales, la humanidad está agotada y quiere más humanidad y un sentido de pertenencia.

Las personas intercambian ideas sobre su ser interior. Quieren incluir todo y a todos como sea posible, apreciar e integrar a las minorías y las personas desfavorecidas. Aspiran a pensar holísticamente, compartir la riqueza de la experiencia y aprender a través de la escucha activa. Las decisiones deben basarse en el consenso, lo que puede llevar a un punto muerto debido a las discusiones en curso. Desea crecer juntos y experimentar solidaridad en la comunidad. La psicología toma la delantera y la soberanía de la interpretación en el autodescubrimiento. Las instituciones religiosas pierden su posición de poder. Puede aumentar su conciencia a través de las drogas psicodélicas. Instituciones como el matrimonio son cuestionadas y descartadas como ideología polvorienta. Buscas compañeros en tu vida, vives juntos como parejas solteras y los niños son tratados más como parejas. Surgen familias de retazos, se toleran las parejas del mismo sexo, los círculos de amigos y las redes sociales reemplazan las relaciones familiares disidentes.

\footnotetext{
${ }^{3}$ Rifkin Jeremy, die empathische Zivilisation, Wege zu einem globalen Bewusstsein, Frankfurt/New York 2010, zitiert nach Schloemann Johannes, in Süddeutsche Zeitung vom 19.01.2010, S.11
} 


\section{“Acaso la roca no se convierte en un "tú" extraño, justo cuando me dirijo a ella?"4}

Novalis

Las personas se reconocen de nuevo en la naturaleza. Poetas como Ralph Waldo Emerson y Henry David Thoreau piden un estilo de vida simple y un retorno a la naturaleza.

Poco a poco se está volviendo claro para las personas que todo el planeta tierra está en un equilibrio sensible, que puede ser perturbado fácilmente, de hecho, ha sido perturbado por nuestra influencia.

Te pones de pie y luchas contra el uso de insecticidas, así como contra la tala de los bosques primitivos. La tierra ya no puede ser explotada. En cierto modo, la naturaleza recupera su alma. La sabiduría de los pueblos indígenas aparece cada vez más en foco: uno busca en su sabiduría métodos de curación alternativos, un nuevo sentido, sí, una nueva cosmovisión y admira estar incrustado en la naturaleza.

\section{V.6.3 turismo}

\section{V.6.3.1 turismo historico}

Se producen retiros de autodescubrimiento, viajes a visitar á gurús en la India en Ashrams, intercambio en campamentos juveniles internacionales, ayuda voluntaria en el extranjero, búsquedas de visión natural, retiros de meditación, entre otros.

\section{V.6.3.2 turismo actual}

Turismo suave y sostenible, viajes compatibles con el medio ambiente y la sociedad, uso sostenible de los destinos turísticos, respeto por las tradiciones culturales de los países visitados, uso cuidadoso de los recursos naturales, ecoturismo.

Comercio justo en turismo para mejorar las condiciones de vida de los empleados de turismo y propietarios de pequeñas empresas, asegurar sus medios de vida y permitirles tener una existencia digna. Los socios crean transparencia sobre sus actividades y respetan plenamente la democracia y la participación, y construyen y mantienen relaciones equitativas basadas en la asociación. El objetivo del desarrollo del comercio justo en el turismo no es simplemente crear un nuevo nicho, sino mostrar el camino, cómo toda la industria del turismo puede operar de una manera socialmente justa.

El desafío es realizar un turismo que sea integral (económico, ecológico, social y cultural) sostenible o que contribuya al desarrollo sostenible y satisfaga las expectativas de los

\footnotetext{
${ }^{4}$ Novalis, „Die Lehrlinge zu Sais“, zitiert nach Lothar Pikulik, Frühromantik, München 2000, S.251 auf Deutsch: Wird nicht der Fels ein eigentümliches Du, eben wenn ich ihn anrede?
} 
Cadernos CERU, Série 2, Vol. 31, n. 1, jun. 2020

viajeros de unas vacaciones relajantes y atractivas, así como las de los lugareños en el destino de nuevos ingresos, respeto sus medios de vida y diversidad cultural, así como su dignidad. ${ }^{5}$

\section{V.7. nivel 7 - Espíritu y espacio creativo}

\section{V.7.1. el individuo}

Desde este nivel de conciencia, las personas tienen una visión general de todo el camino del desarrollo espiritual por primera vez. Aprecia cada una de las etapas anteriores porque se da cuenta de lo valiosas e indispensables que fueron. Esta visión moderada de su propia evolución es nueva y revolucionaria. Los niveles anteriores de conciencia solo aceptaron su propia cosmovisión y devaluaron a todos los demás. No se dio cuenta de que las diferentes condiciones de vida requerían diferentes sistemas de valores y comportamientos.

El hombre ha hecho las paces con su pasado. Esto elimina temores y limitaciones. Esto abre una nueva forma de resolución creativa de problemas. Como acepta todos los niveles de conciencia anteriores como equivalentes, ahora puede recopilar información en todos los niveles de conciencia. Confía en su experiencia y su enfoque poco convencional porque puede pensar en todos los niveles, reconocer patrones de relación e incorporar la interconexión múltiple de todas las estructuras.

El futurólogo Matthias Horx ${ }^{6}$ llama a esta habilidad "pensamiento fluido", que puede percibir procesos, resonancias e interacciones en varios niveles y cómo los elementos contradictorios están relacionados y tienen sentido.

Una persona en el séptimo nivel de conciencia usa su habilidad para pensar, amar y actuar igualmente para una visión abierta y multi-perspectiva del mundo. Curiosamente, estas fueron también las características que la cosmovisión inca utilizó como criterio para evaluar el nivel de madurez de una persona: Yachay, la capacidad de pensar, Munay, la capacidad de amar, LLankay, la capacidad de actuar o la efectividad de una persona y la capacidad de usar estos tres factores por igual. Si un individuo combinaba las tres habilidades y podía controlarlas de manera intencional e incondicional, era muy reconocido en la sociedad como líder.

Dado que este nivel de conciencia solo se ha introducido recientemente en la sociedad moderna, las personas de este nivel a menudo se sienten solas porque hay muy pocos seres humanos que compartan su punto de vista. Ken Wilber, filósofo, autor y visionario estadounidense, estima que la proporción de la población mundial es de alrededor del uno por

\footnotetext{
${ }^{5}$ fuente: Arbeitskreis Tourismus und Entwicklung.

${ }^{6}$ Horx, Matthias, „Das Buch des Wandels, wie Menschen Zukunft gestalten“, München, 2009, S. $219 \mathrm{ff}$.
} 
Cadernos CERU, Série 2, Vol. 31, n. 1, jun. 2020

ciento. ${ }^{7}$ En esta etapa, la gente inicialmente se siente como en el exilio, en una especie de tierra de nadie. Sin embargo, sienten que esta es la única forma de explotar su potencial y seguir su visión del aprendizaje permanente en todos los niveles posibles. Absorben la información de manera intelectual, emocional, intuitiva y contemplativa. Aprecian estar solos como fuente de autoconciencia y autodeterminación. La autonomía personal y la plena responsabilidad de sus vidas es importante para ellos.

Las personas en el séptimo nivel de conciencia intentan encontrar soluciones no convencionales. Pero su motor no es el lucro. La orientación ambiental, la igualdad, el compromiso social, los procesos grupales orientados al consenso son una cuestión de rutina para ellos; la world wide web es tu kit creativo. Son innovadores y trabajan en red a nivel internacional. El conocimiento y la experiencia tienen prioridad sobre los símbolos de estado, las demandas individuales de poder o las posesiones materiales. Prefieren la independencia personal, pero están estrechamente relacionados emocionalmente con su trabajo. Pueden combinar contradicciones internas y posiciones opuestas en un tercero superior.

Son excelentes mentores y estan encantandos de ayudar a otros en su deseo de autodesarrollo y autodesarrollo. Forman relaciones sin ser posesivos, con humor, profundidad y tolerancia.

\section{„Maldita sea, todos tienen derecho a ser quienes son ${ }^{\star 8}$}

Clare W. Graves

La oración dictada por Clare W. Graves se acerca mucho al núcleo del séptimo nivel de conciencia, porque en contraste con todos los niveles de conciencia anteriores, que se desprecian y devalúan entre sí, ha desarrollado una nueva habilidad humana para la cual todavía no hay un término fijo en nuestro idioma, dar. Puedes llamarlos pensamiento integral, sistémico o sintético. La capacidad de soportar contradicciones, pensar paradojas y reconocer principios contradictorios en igualdad de condiciones.

\section{V.7.2 cultura y sociedade}

Por primera vez en la historia, en el siglo XX surgió la situación de que tres niveles de desarrollo están presentes simultáneamente y casi con la misma fuerza dentro de una sociedad. Los niveles cuarto y quinto y sexto existen uno al lado del otro.

\footnotetext{
${ }^{7}$ Wilber, Ken, Integral Psychology: Consciousness, Spirit, Psychology, Therapy, 2000

${ }^{8}$ McIntosh Steve, Zitat in „Integrales Bewusstsein und die Zukunft der Evolution. Wie die integrale Weltansicht Politik, Kultur und Spiritualität transformiert", Hamburg, 2009, S.88 Deutsche Übersetzung: Verdammt noch mal, jeder Mensch hat das Recht, der zu sein, der er ist
} 
Cadernos CERU, Série 2, Vol. 31, n. 1, jun. 2020

Según un estudio publicado en 2000 por el sociólogo estadounidense Paul Ray se podrían nombrar tres "culturas" claramente distinguibles: la tradicional, la moderna y la culturalmente creativa. El grupo más grande, es decir, el 50\% provino del cuarto nivel de conciencia, el cuarto y quinto nivel de conciencia representaron cada uno el $25 \%$. La base de la investigación fue una investigación de valor durante un período de 13 años, en el que se entrevistó a un total de 100.000 estadounidenses. $^{9}$

Si desea unir este acto de equilibrio, necesita personas del séptimo nivel de conciencia, porque tienen la capacidad de mediar la integración sistémica entre los tres grupos. Se trata de nada menos que la supervivencia física de toda la humanidad. Hay que encontrar soluciones a amenazas fundamentales como la superpoblación, la degradación ambiental, el armamento, el terrorismo, los sistemas financieros mundiales y las pandemias.

Una sociedad integradora sistémica reconoce que los problemas globales como la catástrofe climática, la crisis financiera o las pandemias globales ya no pueden ser resueltos por estados individuales, gobiernos o iniciativas locales. Aumenta la conciencia de que la tierra es un ecosistema único en el que todo está relacionado con todo.

\section{V.7.3 turismo actual}

Nómadas digitales, viajeros individuales que buscan contacto con los residentes del destino de viaje y no se ven a sí mismos como turistas, sino como parte de una comunidad global inmersa en la cultura del destino de viaje y del ocio creativo.

\section{turismo hoy}

Desde el siglo XX, por primera vez en la historia, tres niveles de desarrollo estuvieron presentes al mismo tiempo y casi con la misma fuerza dentro de una sociedad, por lo tanto, hay tres formas diferentes de turismo.

\section{Turismo de cuarto nivel}

El turismo de masas, el turismo como monocultivo, la industria del entretenimiento, las idiosincrasias culturales de los países se retrasan. El extranjero se adapta a los deseos de los huéspedes y a los requisitos del operador turístico, creando así un telón de fondo, un daño enorme para el medio ambiente y la naturaleza, daños climáticos debido a medios de transporte intensivos en emisiones, eliminación de residuos y el mayor consumo de productos naturales. En relación a los recursos naturales la contaminación del agua y del suelo, el aumento del consumo de energía, el deterioro de biotopos y ecosistemas, la desfiguración estética de paisajes naturales y culturales cultivados a través de infraestructuras turísticas van en aumento.

\footnotetext{
${ }^{9}$ https://enacademic.com/dic.nsf/enwiki/213216
} 


\section{Turismo de quinto nivel}

Un segmento de alto precio de viajes de larga distancia y turismo de aventura como un paquete y viajes de crucero. Las peculiaridades culturales de los países son reconocidas y valoradas siempre que no perturben las vacaciones y se ofrezcan como entretenimiento folclórico. Los aspectos culturales del destino visitado continuarán adaptándose a los deseos de los huéspedes y los requisitos del operador turístico y seguirán siendo el telón de fondo. La conciencia culpable debido al daño al medio ambiente y la naturaleza, el daño climático, el deterioro de los ecosistemas, etc., se intenta evitar al reservar con operadores turísticos que prometen sostenibilidad. Sin embargo, esto no se verifica más a través de un seguimiento adecuado.

\section{Turismo de sexto nivel}

Turismo suave y sostenible, viajes ambiental y socialmente responsables, uso sostenible de los destinos turísticos, respeto a las tradiciones culturales de los países visitados, uso cuidadoso de los recursos naturales, ecoturismo, limitación numérica de los turistas.

\section{Cómo podría ser el futuro del turismo}

\section{VI.1. la visión de un enfoque ecológico profundo}

\section{VI.1.1 definición de ecología profunda}

La ecología profunda es una filosofía ambiental y natural "holística" espiritual que lucha por una vida en armonía con la naturaleza. El filósofo noruego Arne Ness acuñó este término a principios de la década de 1970. Él dice: “Se trata de armonía ecológica y equilibrio ecológico. No se trata solo de utilizar los recursos ambientales suavemente, como se utilizó el término ecología. Los seres humanos deben asumir su papel de "guardianes" de su propio mundo o medios de vida."10 También se trata de cómo podemos diseñar una forma de vida diferente y más humana, para no vernos más como la corona de la creación y para darte el derecho de explotar la naturaleza, de usarla sin medida ni objetivo.

También se trata de empatía por todo lo vivo, para poder crear "igualdad de biosfera". En el contexto científico, la ecología profunda se inspira en la hipótesis de Gaia, que dice: la tierra es un organismo vivo y consciente.

Se trata de unificar cuatro factores, a saber:

- el pensamiento,

- la sensación

\footnotetext{
${ }^{10}$ Ness, Arne, Die Zukunft in unseren Händen: Eine tiefenökologische Philosophie (Edition Trickster, 2013); 978-3-7795-0376-7
} 
- la actuación

- y la espiritualidad, es decir, la conexión con todo y todo lo que es

Joana Macy, activista ambiental e ícono de la ecología espiritual profunda agrega en conversación con el Dr. Geseko von Lüpke ${ }^{11}$ :

"La ecología profunda difiere de la ecología tradicional en que va más allá del antropocentrismo, que siempre busca reparar todos los problemas ecológicos para el beneficio, beneficio o beneficio de las personas. En cambio, la ecología profunda se centra en los ciclos esenciales y sistemas de la naturaleza misma, para hacernos servidores de la salud del todo más amplio. Y eso nos libera, creo, para actuar con más sabiduría e inspiración. Este enfoque también nos da un sentido de pertenencia a nuestro universo Nos saca del sentimiento de aislamiento, alienación y explotación, hacia un sentimiento de comuión con la tierra viva y todas sus manifestaciones. Y eso tiene un efecto muy importante: desencadena nuestra voluntad de ayudar y nuestra creatividad".

La ecología profunda no se puede lograr "repensando". No se trata de cambiar la estación de radio rápidamente. Tampoco se tiene una práctica religiosa experimentada desde la infancia. Podría caer rápidamente por conversión. Se trata de experimentar una conexión profunda y eso se experimenta como absolutamente cierto por dentro, no solo para agregarlo a tu vida como un estilo de vida nuevo y moderno.

\section{VI.1.2 conciencia ecológica profunda}

En mi opinión, las personas del octavo nivel de conciencia deben implementar enfoques ecológicos profundos. Una asociación de pensadores integrales que trabajan juntos en todo el mundo para resolver problemas como la protección del clima global, el control de los sistemas financieros mundiales, el desarrollo económico y cultural de continentes enteros y la configuración de un nuevo tipo de turismo.

Encontraremos soluciones en un nivel cosmocéntrico de reflexión de la conexión de todo lo que es como una gran unidad dinámica. Esta conexión multidimensional, que los pueblos primitivos todavía experimentaron mágica y temerosamente en el segundo nivel, puede servir como la base del octavo nivel de conciencia con el conocimiento actual, especialmente la teoría cuántica. Las personas del octavo nivel de conciencia se identifican entre sí y pueden hacerlo combinando polaridades como "acción y contemplación, evaluación y aceptación, ambigüedad y ambigüedad, pensamiento absoluto y relativo, lógico y paradójico, duda y autoconfianza, conocimiento e ignorancia.

Aceptar incondicionalmente. Su lenguaje es claro, muy directo, juguetón, pictórico y humorístico. Inspiran a las comunidades, pero al mismo tiempo aspiran a ser redundantes.

\footnotetext{
${ }^{11} \mathrm{https} / / /$ tiefenoekologie.de/12-politk-des-herzens/9-joanna-macy-die-welt-als-geliebte
} 
Debido a su estructura compleja, pueden ser tanto observadores silenciosos como diseñadores comprometidos que presentan sugerencias para una transformación global y multicultural que va mucho más allá de su propia vida." 12

Cuando muchos individuos en el séptimo nivel de conciencia se interconectan para formar un "cerebro global"13, se convierte en una "inteligencia excesivamente sumativa"14. La intuición, el instinto, el conocimiento y la sabiduría serán necesarios para esto. El economista alemán C. Otto Scharmer describe cómo pueden iniciarse y formarse procesos de cambio de gran alcance: las personas que desean crear algo realmente nuevo deben conectarse "con la fuente más profunda de su ser auténtico"15. Por cierto, Scharmer es un empleado del reconocido Instituto de Tecnología de Massachusetts en Boston y no un nuevo gurú.

Si reconocemos que somos fractales, es decir, repeticiones de patrones en pequeños y grandes, también entendemos que solo tenemos que trabajar como un órgano planetario que funciona con otras grandes asociaciones de la tierra, como los océanos, las montañas, el aire, las plantas y el reino animal para crear una inteligencia colectiva.

\section{VI.1.3 cómo la conciencia ecológica profunda podría afectar el turismo}

Las crisis y las situaciones de cambio son mensajeros del cambio de un nivel de conciencia a otro. Siempre hay una gran inestabilidad y nadie puede predecir a dónde irá el viaje. Es imposible regular el cambio de conciencia de toda una sociedad, pero podemos establecer el curso necesario como pioneros.

El antropólogo, periodista y escritor, Dr. Geseko von Lüpke ya habló en 2012 sobre el significado de una crisis:

"Las crisis y las transiciones siempre se acumulan de tal manera que primero hay una fase en la que se prepara, y luego hay una fase umbral en la que generalmente no se puede mirar y todo se siente bastante caótico y luego llega el cambio nueva autoimagen, una nueva identidad. Eso funciona tanto individual como colectivamente. Lo que está en el medio, este período umbral de una transición desde una vieja visión del mundo, desde el viejo modo económico de comercio, desde una vieja visión del mundo, una vieja autoimagen, si eso se desintegra, hablamos de crisis".

Von Lüpke supone que las crisis tienen el potencial de encontrar nuevas soluciones mientras el sistema de colapso está abierto y que se pueden crear nuevas identidades o niveles

\footnotetext{
${ }^{12}$ Küstenmacher, Werner Tiki und Marion, Haberer Tilmann et.al, Gott 9.0, wohin unsere Gesellschaft spirituell wachsen wird, Gütersloher Verlagshaus, 2010, S. 197

${ }^{13}$ Kruse Peter, „,next practice - „erfolgreiches Management von Instabilität. Veränderung durch Vernetzung“, Offenbach, 2004, S.14

${ }^{14}$ Kruse Peter, „,next practice - „erfolgreiches Management von Instabilität. Veränderung durch Vernetzung“, Offenbach, 2004, S.133

${ }^{15}$ Scharmer, C.Otto, „,Theorie U. Von der Zukunft her führen“, Heidelberg 2009, S. 37
} 
Cadernos CERU, Série 2, Vol. 31, n. 1, jun. 2020

de conciencia. "Las crisis nos permiten ver que actualmente estamos en una delgada corteza de orden y estabilidad que puede romperse en cualquier momento".

Si tenemos el coraje de sumergirnos en las perlas de nuestros recursos del pasado, encontraremos entre ellos el conocimiento que necesitamos para crear un futuro sostenible.

El modelo de Ken Wilber de los cuatro cuadrantes podría ser una herramienta para evaluar un nuevo turismo pandémico: ${ }^{16}$ :

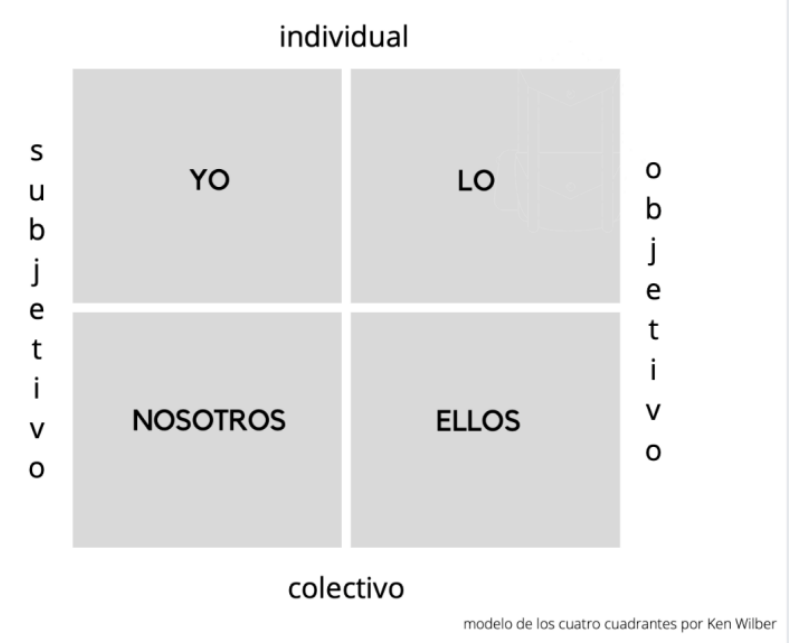

El primer cuadrante (ArI, arriba a la izquierda) trata sobre la posición del ego, en la que se explora la autoconciencia y la autoexpresión. La perspectiva del espectador es necesaria y significativa, ya que cualquier intento de describir la realidad sin involucrar al sujeto es incompleto. Sus propios sentimientos, ideas y estética personal son decisivos al evaluar este cuadrante.

El segundo cuadrante (ArD, arriba a la derecha) trata sobre el objetivo fuera de la perspectiva, un enfoque común de la ciencia moderna. Las cifras, datos, hechos, pruebas empíricas, evaluaciones de valores y normas medidas, pruebas de laboratorio o encuestas comprensibles a través de encuestas pueden proporcionar información útil.

El tercer cuadrante (AbI, abajo a la izquierda) es el cuadrante cultural de las cosmovisiones. Aquí es donde pertenecen la conciencia grupal, las perspectivas sociales y sociales, la aceptación cultural o el rechazo de las formas y tradiciones de vida. Esta perspectiva le da voz a los valores colectivos, sentimientos y visiones del mundo.

El cuarto cuadrante (Abd, abajo a la derecha) representa los factores materiales, económicos y sociales dentro de los sistemas que crean infraestructuras.

\footnotetext{
${ }^{16}$ Wilber, Ken, „Eros, Kosmos, Logos. Eine Jahrtausend-Vision“, Frankfurt am Main, 2001, S. 11-96
} 
Cadernos CERU, Série 2, Vol. 31, n. 1, jun. 2020

En un proceso de toma de decisiones en el octavo nivel, no hace falta decir que puede especificar el cuadrante del que proviene la información y puede incluir todas las perspectivas y aspectos por igual. También puede determinar de qué nivel de desarrollo surge la necesidad del transportista de información. ¿La necesidad proviene del deseo de cambiar la falta de poder afrontar del hambre y la indefensión, el sentimiento de estar perdido, el desmayo, el caos, la heteronomía o la injusticia y la desigualdad?

Si reconocemos las necesidades horizontales y verticales de todos los participantes en los procesos de toma de decisiones, recibimos soluciones alternativas prospectivas $\mathrm{y}$, por lo tanto, podemos crear el mejor futuro posible y no solo el más probable.

Si ahora traducimos la matriz de Wilber al turismo, la asignación de los cuadrantes podría verse así:

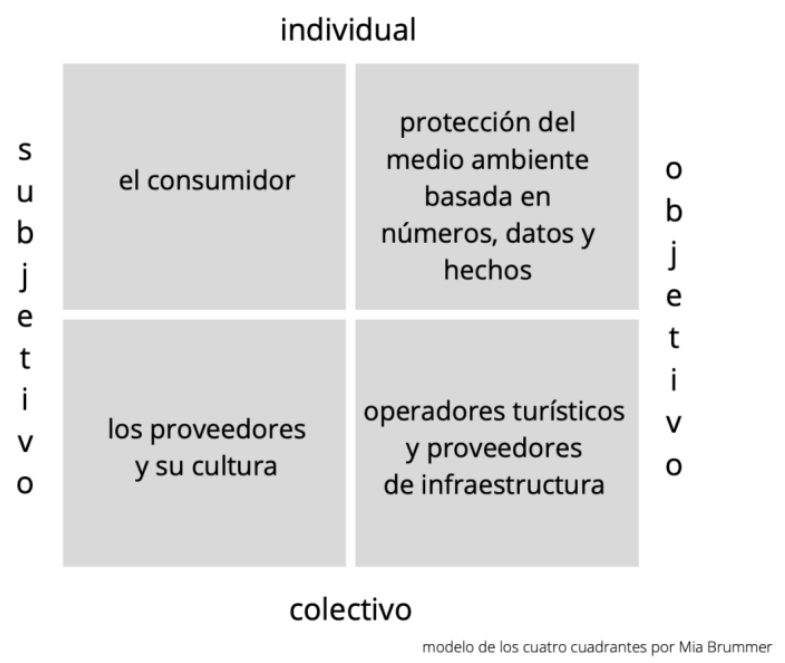

\section{Conclusión}

\section{" el ser es donde está la acción "17}

Ken Wilber

Solo como nosotros podremos enfrentar los desafíos. Un nosotros que se arremanga las mangas de su camisa y no permanece congelado ante los desafíos, sino que actúa lo más rápido posible.

Al hacerlo, podemos y debemos usar recursos que aún no hemos usado. Además de las fuentes anteriores de estadísticas y resultados de investigación, también tenemos que incluir

\footnotetext{
${ }^{17}$ Wilber, Ken, „Das Wahre, Schöne, Gute. Geist und Kultur im 3. Jahrtausend“, Frankfurt am Main, 2002, S.327 Deutsche Übersetzung: das Sein ist dort, wo das Handeln ist
} 
campos de conocimiento ampliados. Uno de ellos es, sin duda, la antropología social. El Dr. Bernardo Muñoz Aguilar que plantea:

"La antropología social como ciencia es una observadora privilegiada del comportamiento humano, de sus culturas y de su devenir. Es desde esta óptica que aquí se aborda el turismo, el turismo sostenible y la necesaria ecología profunda en su accionar futuro. Usa la historia como una ciencia auxiliar para evidenciar y proponer futuros logros para la humanidad. En este caso concreto nos ocupamos desde la antropología hacia el turismo y sus actores, los territorios, los viajeros y los visitados para sugerir nuevos alcances que optimicen su accionar. Serán estos actores y también los antropólogos y antropólogas los que deberán marcas las nuevas rutas a recorrer juntos con la Pachamama.

¡Esto es una gran revolución! Y tenemos la posibilidad de ser parte de ella, para de alguna forma incidir en la enseñanza del turismo sostenible y de ecología profunda." 18

Si nos permitimos extraer de la abundancia de conocimiento de todos los participantes en la discusión, reconocerlos por igual e incluirlos en el proceso de toma de decisiones sin devaluación, podemos usar el oceano de los potenciales para encontrar soluciones que hacen del turismo pospandémico un renacimiento triunfante de la idea original de viajar: como un espacio para la exploración interior y exterior, como un descubrimiento en el espejo de otras culturas, como una extensión de uno mismo y una inmersión en el campo eterno de la enseñanza y la aprendizaje.

\section{Agradecimientos}

Me gustaría aprovechar esta oportunidad para agradecer a una persona sin la cual nunca hubiera abierto la puerta a mi océano de los potenciales. A través de su estímulo incansable, abrió nuevos horizontes en mí y la creencia de que mi tipo de pensamiento en red en el séptimo nivel (que durante mucho tiempo se ha reído de las personas con orientación científica) no es una mala interpretación. A través de él, ahora soy parte de un equipo interdisciplinario que no se ocupa de las etiquetas, pero que se permite soñar e implementar realidades juntas en el octavo nivel. Gracias a mi gran mentor, el Dr. Bernardo Muñoz Aguilar.

\section{Bibliografía}

- Bahr, Ann Marie B., Marty, Martin E.: Indigenous religions. Infobase Publishing, New York 2005. Ayllu and Ayni, S. 135f.

\footnotetext{
18 2020: Muñoz, Bernardo: "La educación en el turismo o el turismo con educación antes de la Pandemia, durante la Pandemia y post Pandemia.", Centro de Estudios Urbanos y Rurales, CERU, Universidad de Sao Paulo, Brasil.
} 
Cadernos CERU, Série 2, Vol. 31, n. 1, jun. 2020

- Graves, Clare W. Levels of Existence: An Open System Theory of Values. In: Journal of Humanistic Psychology, November 1970

- Graves, Clare W. „The Neverending Quest “, Cohan \& Todorovic, 2007

- Horx, Matthias, „Das Buch des Wandels, wie Menschen Zukunft gestalten“, München, 2009

- Lozano, Alfredo "CUSCO-COSQO. -MODELO SIMBÓliCO DE LA COSMOLOGía ANDINA", 1990

- Lüpke, Geseko, Politik des Herzens, Nachhaltige Konzepte für das 21.Jahrhundert. Gespräche mit den Weisen unserer Zeit. ARUN-VERLAG, ISBN-Nr. 3935581335

- Ness, Arne, Die Zukunft in unseren Händen: Eine tiefenökologische Philosophie, Edition Trickster, 2013

- Ray, Paul H.; Anderson Ruth: The Cultural Creatives. How 50 Million People Are Changing the World, New York (Harmony Books) 2000

- Scharmer, C. Otto, „Theorie U. Von der Zukunft her führen“, Heidelberg 2009

- Wilber, Ken, Integral Psychology: Consciousness, Spirit, Psychology, Therapy, 2000

- Wilber, Ken, „Eros, Kosmos, Logos. Eine Jahrtausend-Vision“, Frankfurt am Main, 2001

- Wilber, Ken, „Das Wahre, Schöne, Gute. Geist und Kultur im 3. Jahrtausend“, Frankfurt am Main, 2002. 